\title{
UN NUEVO CAMPAMENTO ROMANO EN LA CUENCA DEL DUERO: EL RECINTO CAMPAMENTAL DE UXAMA (SORIA)
}

\author{
POR \\ CARMEN GARCÍA MERINO \\ Universidad de Valladolid
}

\section{RESUMEN}

Se da a conocer la existencia de un campamento romano de morfología imperial en las inmediaciones del casco urbano de Uxama Argaela (Osma, en Soria). La posición de este recinto, el más oriental de los conocidos en la mitad norte, lejos de las minas y de los campamentos estables, puede contribuir a dar luz sobre el papel del ejército en Hispania durante el Imperio.

\section{SUMMARY}

This paper presents evidences of a new Roman military camp. Observation of cropmarks on the landscape carried out in a recent aerial reconnaissance over Uxama Argaela (Soria) indicates the existence in the area of a small military camp during the Roman imperial times. It suggests that this camp was probably linked to a role of Roman Army as administrative tool.

En esta breve nota queremos dar a conocer la existencia de un nuevo yacimiento menor englobado en el conjunto arqueológico de Uxama. Nos referimos a una estructura identificable como campamento romano que se documenta en un fotograma aéreo obtenido en $1991^{1}$. Con posterioridad se han efectuado otras tomas que han verificado la primera impresión ${ }^{2}$ y finalmente se ha tratado informática-

1 Este vuelo es uno de los varios realizados para obtener información en el marco del proyecto de investigación que sobre esta ciudad de Uxama estamos llevando a cabo desde 1976, con una serie de campañas de excavaciones subvencionadas desde 1982 por la Junta de Castilla y León, realizadas con un equipo de la Universidad de Valladolid y con un Plan director para el yacimiento, actualmente en desarrollo.

2 La mayor parte de los reconocimientos los realizamos con el arqueólogo Julio del Olmo Martín, especialista en prospecciones aéreas, autor de varias series de fotografías, que comenta así la imagen en color del campamento: «El recinto objeto de estudio fue fotografiado por vez primera en prospección arqueológica en la mañana del 21 de Mayo de 1991 pero los mejores resultados se obtuvieron en un vuelo posterior, en la mañana del 28 de junio de 1994, gracias a un contraste de coloración en la siembra de cereal temprano que se encontraba en pleno proceso de maduración. De las trazas descubiertas se pueden asimilar como pertenecientes a posibles fosos las exteriores, más oscuras, originadas por mantener una mayor concentración de humedad re- mente la imagen para obtener una representación planimétrica fiable ${ }^{3}$

El recinto está situado al sur de la ciudad, a $1 \mathrm{~km}$ de distancia y en la otra orilla del río Ucero. Se trata de un espacio rectangular con las esquinas redondeadas, de $185 \times 125 \mathrm{~m}$, orientado en sentido nortesur y delimitado por una franja de $10 \mathrm{~m}$ de anchura que en las fotografías aéreas aparece blanquecina entre dos líneas oscuras. Estas marcas corresponden al terraplén y al foso del recinto. No se observan puertas aunque en el centro del lado septentrional se perciben dos líneas transversales, separadas entre sí $30 \mathrm{~m}$, que lo cortan.

Morfológicamente se puede considerar la estructura como un campamento de pequeño tamaño y escasa duración, con cerca probablemente de madera. Sus dimensiones, 2,3 Ha., lo hacen capaz para una unidad auxiliar o un destacamento legionario. Junto a este recinto y al este parece distinguirse parte de otra estructura del mismo tipo pero mayor y

sidual que retrasa el secamiento de la planta; y una línea más ancha y clara, al interior, se puede interpretar como un posible ager. Esta tonalidad más clara que el resto del cereal se debe precisamente a ser un terreno más compactado y retener peor la humedad que el conjunto de la parcela».

${ }^{3}$ El tratamiento informático ha sido realizado por el también arqueólogo Giacomo Gillani, quien nos ofrece la siguiente información sobre el proceso: «Para el tratamiento de la imagen de esta estructura, detectada en fotografía aérea oblicua, hemos trabajado sobre una ortofotografía del Ministerio de Hacienda (Hoja E5 037704 04) elaborada a partir de un vuelo, efectuado también en mayo de 1991. Tratándose de un producto corregido, la ortofotografía ha permitido medir con exactitud las dimensiones: el lado mayor mide $185 \mathrm{~m}$ y el menor 125 mientras que la distancia entre el recinto interior y el exterior es de $10 \mathrm{~m}$. Para poder mejorar la imagen de los restos detectados, procedimos a digitalizar mediante un scanner A4 el campamento a una resolución de 400 DPI en tonos grises. A continuación pasamos al análisis de la imagen mediante el prográma de procesamiento de imágenes Adobe Photoshop. En la elaboración se han ecualizado los tonos grises y se ha mejorado el brillo y el contraste para poder enfatizar las evidencias. Asimismo la inversión en negativo de la imagen nos permitió mejorar sensiblemente la apreciación de las huellas del foso y la aplicación del filtro Emboss ayudó a resaltar las evidencias». 


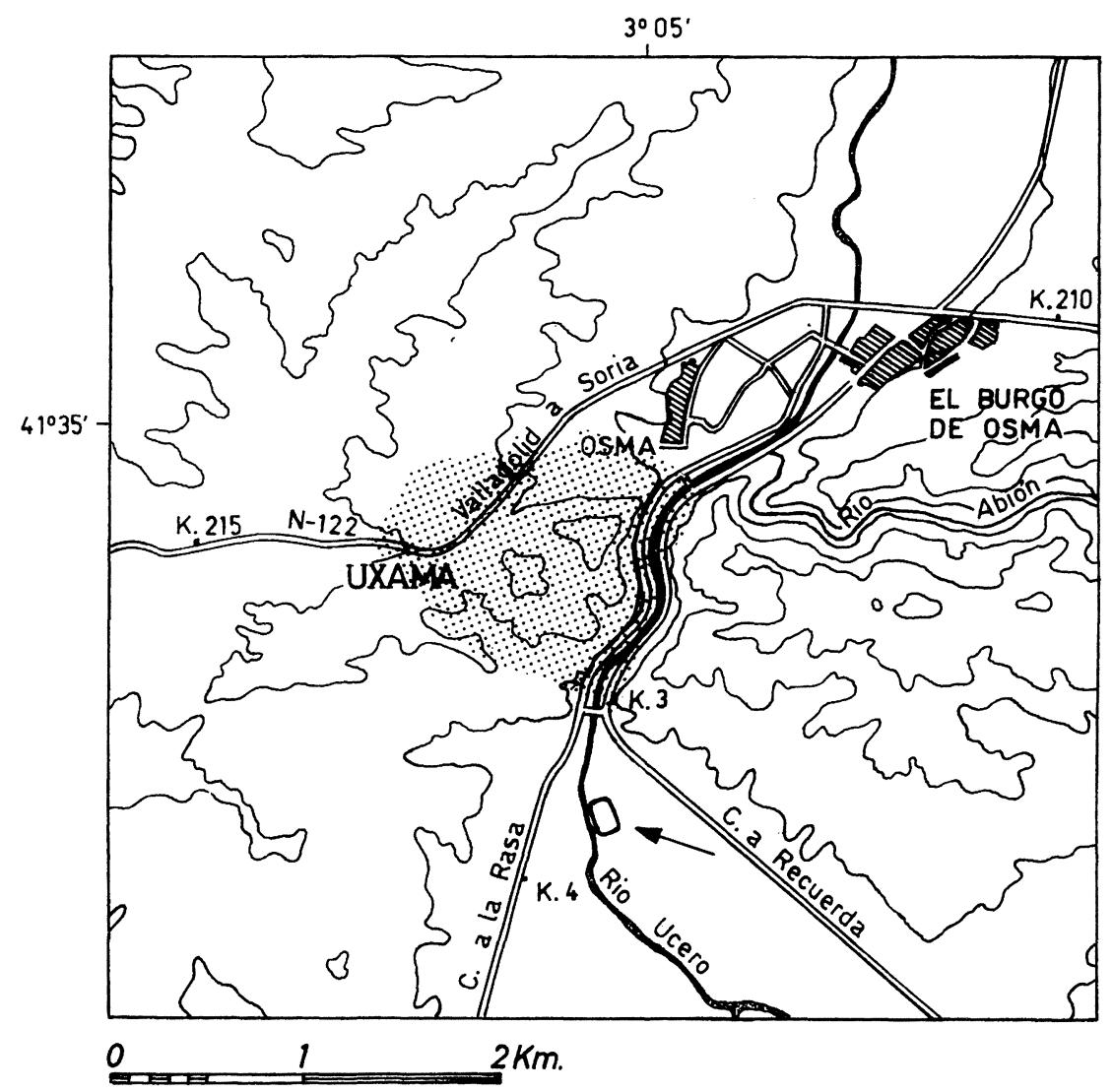

Fig. 1.-Calco del Mapa MNT, Hoja 377 (Burgo de Osma), con la situación del campamento de Uxama.

con una orientación ligeramente distinta (fig. 2). El sector queda fuera de la zona donde se ha previsto excavar a corto y medio plazo y está pendiente de una prospección sistemática. En una primera inspección superficial ha proporcionado materiales cerámicos altoimperiales, sobre todo terra sigillata hispánica y cerámica común, datos que no permiten por ahora mayores precisiones, especialmente porque en esa zona del territorio de la ciudad hay numerosos yacimientos subsidiarios de ella separados entre sí a escasa distancia.

El campamento se sitúa en un llano ligeramente elevado sobre el cauce del Ucero, en el interfluvio de los ríos Abión y Sequillo. El emplazamiento del recinto es excelente para el abastecimiento de víveres, agua y forraje y goza de una óptima visibilidad del entorno. La situación es también muy buena desde el punto de vista del control de las comunicaciones porque se encuentra sobre un pequeño nudo viario en el que destaca sobre todo la calzada de Asturica a Caesaraugusta con sus dos tramos, el desvío entre Clunia y Uxama y el secundario por el Duero entre Rauda y Uxama (TIR 1993, K-30) que se cruzaban con la vía de Uxama a Segovia por Termes. Desde el campamento se controla perfectamente todo el sector meridional de la ciudad y muy próximos por el norte están los canales tallados en roca que salen de la Hoz del Ucero y las instalaciones artesanales de Ladrillejos.

Respecto a materiales relacionables con elementos militares en Uxama se puede mencionar el elevado porcentaje de moneda julio-claudia de cecas hispanolatinas partida y contramarcada, si bien puede resultar de la circulación normal en la vecindad de Clunia. También consta el hallazgo, en superficie, de un bronce galo-romano con leyenda GERMANUS INDUTILLI L, fuera del área de dispersión normal de esta moneda -Bélgica, Alemania y Francia- (Guerrero, 1989) y explicable en relación con la presencia de soldados. Esta pieza, excelentemente conservada y acuñada en época augústea, era la única conocida en la Península hasta que recientemente se ha hallado otra en Herrera de Pisuerga (Herreros, Martín y Moreda, 1995, e.p.), sede del campamento de la Legio IV Macedonica.

Se puede mencionar asimismo una carrillera sin 


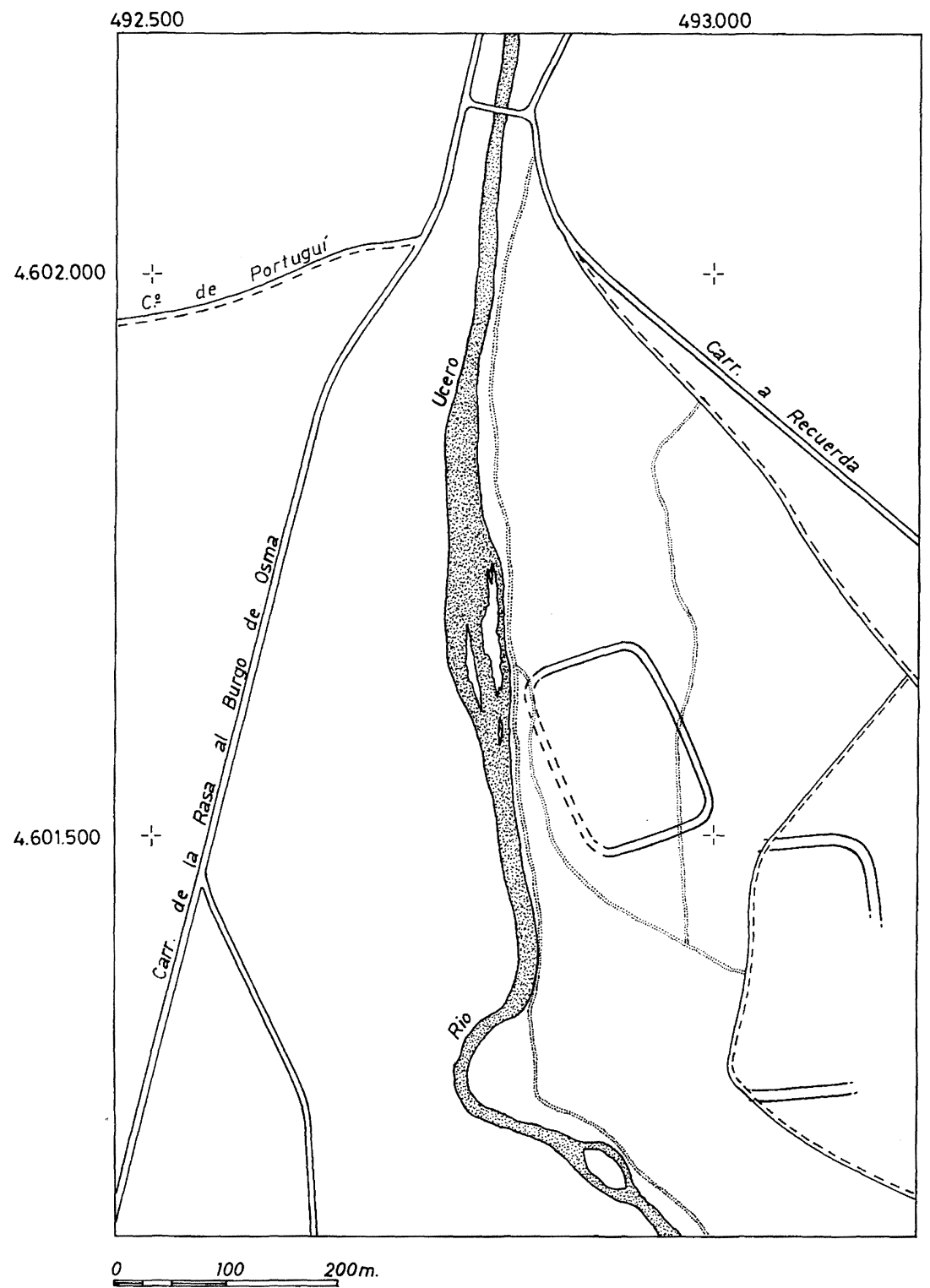

Fig. 2.- Calco de la estructura visible sobre ortofotografía Hoja E5 03770404 del Ministerio de Hacienda.

contexto, ingresada en los fondos antiguos del $\mathrm{Mu}-$ seo Numantino (Argente y García Merino, 1993, 21). Se trata de una pieza de pequeño tamaño perteneciente a un casco muy sencillo, posiblemente del tipo montefortino, asimilable a una variante del tipo A (Rusell-Robinson, 1975,13-250). Está decorada con triple círculo concéntrico, en rehundido, con botón central. Como es sabido, la morfología de un casco y más aún de un elemento aislado difícilmente puede servir de índice cronológico seguro. Aunque parece en este caso de tipo antiguo, tardorrepublicano, pudo utilizarse también en el s. I (Rus-
sell-Robinson, 1975, 13). Finalmente hay dos piezas con epígrafes alusivos a sendos legionarios: un ara de un soldado de la Legio VII, dedicada a fines del s. II a la Fortuna (García Merino, 1970, 413-414 y Jimeno, 1980,37-38) ${ }^{4}$ y la estela funeraria de otro, no hispano, que militó en Germania y pertenecía a la Legión XIIX (García Merino, 1983, 359361 ), numeral que en lugar de XVIII habría posible-

${ }^{4}$ [F]or[tu]nae/ Q(uintus).C[aeci]lius/ Ter[ti]us/ m(iles) [leg(ionis)] VII G(eminae).F(elicis)./v(otum).s(olvit). (ibens) $\mathrm{m}$ (erito). 

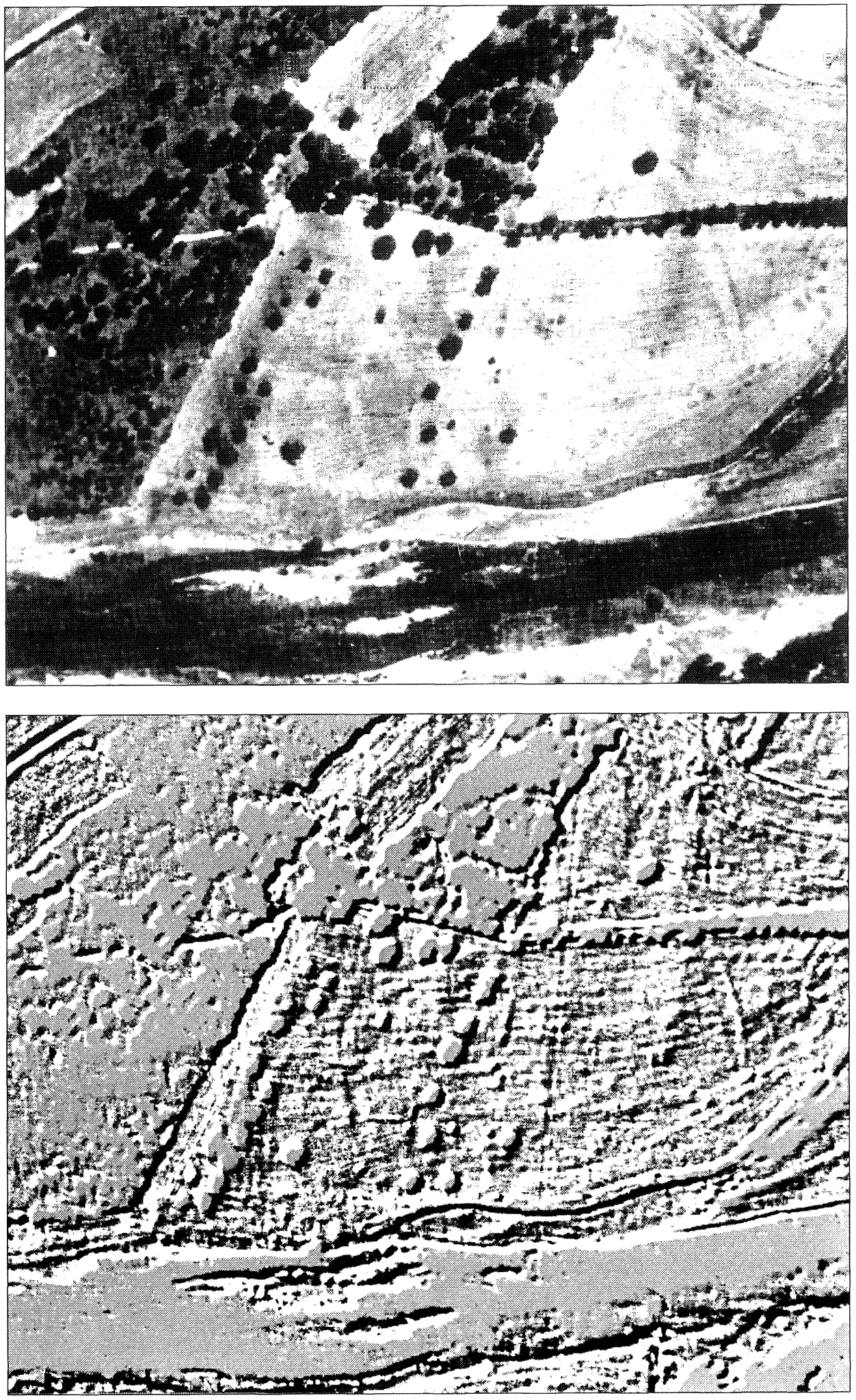

Figura 3-Campamento romano junto al Ucero (Osma). 1. Detalle de la ortofotografía en positivo. 2. La misma imagen sometida a un tratamiento de realce de contrastes. 
mente que leer $X X I I$ y atribuirle una cronología no anterior a época flavia (Gómez Pantoja, 1987, 236) ${ }^{5}$.

Aunque de menor tamaño, el de Uxama es similar a otros campamentos altoimperiales descubiertos también por fotografía aérea como los de Valdemeda (Sánchez-Palencia, 1986) y Castrocalbón (Loewinsohn, 1965) en León y Villalazán (Del Olmo, 1983, 109-118) en Zamora. Los campamentos de época augustea o altoimperiales conocidos se justifican por las fuentes escritas en relación con las guerras cántabras y la actividad bélica o por su cercanía a la zona minera o a campamentos estables (Morillo, 1991; Carretero, 1993). No es ese, evidentemente, el caso del de Uxama, que resulta, por ahora, más difícil de explicar, sobre todo considerando que, si bien tipológicamente se puede adscribir a los del Alto Imperio, su cronología concreta nos es desconocida. Si hay que ponerlo en relación con hechos de armas recogidos en las fuentes clásicas sólo tenemos la alusión a dos: el ataque de Nobilior en 153 a. C. (Apiano, Iber. IX, 47) y el de Pompeyo en 72 a. C. (Floro, Rer. Roman. Lib. VI, II, 10, 9), incompatibles con la morfología del recinto. Por el contrario, si se considera que a partir del s. II el ejército se convirtió en un instrumento de conservación y desarrollo de las regiones al servicio de la política imperial (Roldán, 1989, 272), este recinto puede estar revelando la presencia temporal aquí de una vexillatio para determinadas obras públicas. Tales trabajos comprenderían desde el mantenimiento de vías al amurallamiento de la ciudad en el s. III, si es cierto el papel del ejército como técnico y asesor en el proceso de fortificación urbana en esa centuria (Roldán, 1989, 282).

En definitiva, la existencia de este pequeño campamento ha de cobrar sentido a la luz de una mayor información sobre la actividad de los cuerpos militares de época imperial en la península.

${ }^{5} \mathrm{D}$ (is) m(anibus)/ T(ito) Val(erio) Goliarae/ mil(iti).in. Germ(ania).1/eg(ionis). XIIX. Octav/ia. Elae. marito/ (vacat) optimo/ [f(aciendum) c(uravit)] (Gómez Pantoja, 1987, 235). Es fundamental para la lectura XXII del numeral el hallazgo en Ujo (Oviedo) del epitafio de un primopilario leg(ionis) XIIX que por su currículo debió de pertenecer a la XXII Primigenia mejor que a la XVIII.

\section{BIBLIOGRAFÍA}

APIANO: Iber. White, Harvard, 1964 ( $4^{\mathrm{a}}$ ed.).

Argente, J. L. y García Merino, C. (1993): «Bronces hispanorromanos del Museo Numantino procedentes de Uxama», Bronces y religión romana. Actas del XI Congreso Internacional de bronces antiguos (Madrid, 1990), 9-13.

CARretero, S. (1993): «El cuadrante noroeste peninsular en época romana: Los efectivos militares y sus establecimientos», Brigecio 3, 47-75.

FLORO: Rer. Roman. Schulten, FHA, IV, 1964.

García Merino, C. (1970): «La ciudad romana de Uxama. I», BSAA XXXVI, 383-440.

García Merino, C. (1983): «Addenda a la epigrafía de Uxama», Homenaje al Profesor Martín Almagro Basch III, 359-361.

Gómez-Pantoja, J. (1987): «Two Army-Related Inscriptions from Central Spain», ZPE 68, 234-237.

Guerrero Arroyo, J. (1989): «Un pequeño bronce de ceca galo-romana con la leyenda Cirmanus Indutilli $L$ procedente de Uxama (Osma, Soria)», Celtiberia 77-78, 118-127.

Herreros, M La .; Martín, Ma M.; Moreda, J. (1995): «Hallazgos monetarios en Herrera de Pisuerga (Palencia)» en Actas del III Congreso de Historia de Palencia (en prensa).

Jimeno, A. (1980): «Epigrafía romana de la provincia de Soria». Soria.

LoEWINSOHN, E. (1965): «Una calzada y dos campamentos del conventus Asturum», AEspA 38, 2649.

Morillo Cerdán, A. (1991): «Fortificaciones campamentales de época romana en España», AEspA 64, 135-190.

Olmo Martín, J. del (1995): «Arqueología aérea en tres núcleos campamentales romanos de Zamora y León», Brigecio 4-5, 109-118.

RoldÁn HeRvás, J. M. (1989): Ejército y sociedad en la España romana. Granada.

Russell-RoBINSON, H. (1975): The armour of Imperial Rome. London.

SÁnchez-PAlencia Ramos, F. J. (1986): «El campamento romano de Valdemeda, Manzaneda (León): ocupación militar y explotación aurífera en el NW peninsular», Numantia II, 227-243.

VV.AA. (1993): Tabula imperii Romani. Hoja K-30. (G. Fatás, L. Caballero, C. García Merino y A. Cepas, eds.). Madrid. 